\title{
Adult but not juvenile Barbary macaques spontaneously recognize group members from pictures
}

\author{
Andrea Schell • Kathrin Rieck • Karina Schell • \\ Kurt Hammerschmidt · Julia Fischer
}

Received: 22 September 2010/Revised: 17 January 2011/ Accepted: 27 January 2011/Published online: 12 February 2011

(C) The Author(s) 2011. This article is published with open access at Springerlink.com

\begin{abstract}
For group-living animals, it is crucial to distinguish one's own group members from those of other groups. Studies applying operant conditioning revealed that monkeys living in relatively small groups are able to recognize their own group members when tested with photographs of group members and other conspecifics. Employing a simple looking time paradigm, we here show that Barbary macaques living in two social groups comprising 46 and 57 individuals, respectively, at the enclosure 'La Forêt des Singes' at Rocamadour are able to spontaneously distinguish photographs of members of their own group from those depicting animals that belong to another group. This ability appears to develop with age, as juveniles did not discriminate between members of their own group and another group, although they showed generally more interest in the pictures than did adults. Juveniles frequently displayed picture directed behaviours such as lip-smacking, touching and sniffing in both conditions, indicating that the stimuli were highly salient to them. In conclusion, it appears that at least adult monkeys are able to memorize the faces of a large number of individuals. Whether the difference in behaviour is based on individual recognition of one's own group members or simply the discrimination based on familiarity remains unresolved. However, both mechanisms would be sufficient for group membership identification.
\end{abstract}

Electronic supplementary material The online version of this article (doi:10.1007/s10071-011-0383-8) contains supplementary material, which is available to authorized users.

A. Schell $\cdot$ K. Rieck $\cdot$ K. Schell $\cdot$ K. Hammerschmidt .

J. Fischer $(\bowtie)$

Cognitive Ethology Lab, German Primate Center,

Kellnerweg 4, 37077 Göttingen, Germany

e-mail: fischer@cog-ethol.de
Keywords Barbary macaques - Face discrimination · Individual recognition · Ontogeny · Preferential looking

\section{Introduction}

Individual recognition - the ability to store and retrieve from memory knowledge about specific individuals (Shettleworth 2010) — has been shown in a wide range of taxa (reviewed in Tibbetts and Dale 2007). The recognition of the identity of others can be based on physical appearance, vocalizations, odours or a combination of cues. Such recognition is a core requisite for the development of individualized relationships, as well as the understanding of relationships between third parties (Dasser 1988; Seyfarth and Cheney 1988; Bergman et al. 2003).

In addition to recognizing others individually, it is often crucial for socially living species to collectively distinguish one's own group members from others. There is evidence that nonhuman primates do not only distinguish between member of their own and other groups, but that they also know where specific individuals are ranging. Vervet monkeys, Chlorocebus pygerythrus, for instance, responded more strongly to playbacks of inter-group 'wrr' vocalizations from a subject of a neighbouring group when this sound was presented from another territory than from the neighbouring group's territory (Cheney and Seyfarth 1982). This result indicates that the animals had come to associate a specific individual with its home range and knew the individuals' voice characteristics. Wild chimpanzees, Pan troglodytes, responded differentially to pant hoot vocalizations of group members, neighbours and strangers (Herbinger et al. 2009). Groups of wild Barbary macaques, Macaca sylvanus, had more intense agonistic interactions with members of groups they rarely met, compared to those they met frequently, indicating that they 
remember and categorize individuals of different groups (Deag 1971). This effect is known as the "dear enemy" effect and has also been found in birds (Briefer et al. 2008) as well as in lizards and ants (Whiting 1999; Langen et al. 2000), which were shown to respond more aggressively towards unfamiliar intruders compared to familiar neighbouring intruders (but see Müller and Manser 2007).

While the adaptive value of individual recognition and discrimination of familiar individuals from less familiar ones is well established, the outer limits of these abilities under natural conditions are less clear. Due to methodological constraints, we know to date much more about individual recognition in the auditory domain, because calls can be easily played back to subjects. Acoustic analyses revealed that a large number of vocalizations carry individual signatures (Hammerschmidt and Todt 1995; Janik et al. 2006), and playback studies showed that mother and infant in particular, but also other individuals, recognize each other based on such cues (Fischer 2004; Charrier et al. 2009; Kondo et al. 2010; Sebe et al. 2010).

Recognition of individuals in the visual domain has been predominantly studied in laboratory settings. This research is closely linked to studies that investigated the fundamentals of face perception in nonhuman primates compared to humans. Such studies revealed that humans and nonhuman primates appear to employ similar face-processing strategies (Dahl et al. 2009). The recognition of conspecific faces is based on holistic processing, i.e. the face is processed as an unparsed whole (Dahl et al. 2010). Monkeys as well as humans categorize conspecific faces at the subordinate level of the individual (individuation) rather than at the basic level of the category 'face' (Dufour et al. 2006; Dahl et al. 2007). The level of categorization, however, may depend on experience, as monkeys were shown to be able to individuate members of other species using whole-body images after extended training (Humphrey 1974).

A number of studies have examined whether monkeys distinguish between familiar and unfamiliar conspecific faces (Pokorny and de Waal 2009b; Marechal et al. 2010). Chimpanzees categorize specific individuals using the concept of familiarity while matching pictures of faces of related individuals (Parr et al. 2000). Similarly, dogs, Canis familiaris, (Racca et al. 2010), domestic cattle, Bos taurus (Coulon et al. 2009), and crayfish, Cherax destructor (Van der Velden et al. 2008), distinguish between different individuals, as evidenced by preferential looking time paradigms and behavioural assays. Using operant techniques such as match-to-sample tasks, it was shown that pigeons, Columbia livia (Wilkinson et al. 2010), lemurs, Eulemur fulvus and E. macaco (Marechal et al. 2010), and capuchin monkeys, Cebus apella (Pokorny and de Waal 2009a, b) distinguish between familiar and unfamiliar conspecifics on the basis of photographic representations.
One limitation of instrumental settings is that subjects frequently receive extended training. They are thus repeatedly exposed to pictures and are rewarded for correctly distinguishing between stimuli of the category in question (Thompson and Oden 2000), and sometimes, such procedures allow subjects to get accustomed to the pictures prior to the actual experiment (Bovet and Vauclair 2000). Looking time paradigms such as preferential looking or habituation-recovery paradigms circumvent this problem; yet, they do not tell us much about the use of the cognitive abilities in question under more natural conditions. Therefore, complementary experiments in which subjects are not restrained are important to assess the evolutionary relevance of specific abilities.

In the present study, we examined the spontaneous responses of Barbary macaques to photographic representations of faces. The study was conducted at 'La Forêt des Singes', a large visitor park where about 150 monkeys live in three stable social groups. Monkeys from two of the groups were presented with photographs of members of their own group or one of the other groups and their responses were assessed. Because of the relatively large size of both groups, this study explores the 'outer limits' of facial recognition.

We predicted that subjects would respond more strongly to depictions of unfamiliar subjects. Because previous studies indicated that knowledge of other individuals' characteristics is acquired through experience (Fischer 2004; Sugita 2008; Dahl et al. 2009), we separately analysed the data for juveniles and adults. We predicted that due to experience, adults would show stronger differences in relation to group membership than would juveniles.

\section{Materials and methods}

\section{Study site and subject}

The study was conducted in September 2008 and in May and June 2010 on Barbary macaques living in a 15 ha open outdoor enclosure of the park 'La Forêt des Singes' in Rocamadour, France. The site is a visitor park where all monkeys range freely while visitors are restricted to a path. Food is spread throughout the park and water is provided ad libitum. At the time we conducted the study, the population consisted of approximately 150 individuals living in three stable groups (see Turckheim et al. 1984 for details on park management). Demographic data were kindly made available by Ellen Merz. The members of the two groups interact only very rarely. During the opening hours, the groups are kept in distinct places by the park staff, and during the off-hours, the members of one of the groups move to a separate enclosure. 
Stimulus selection

We took portrait photos for stimuli using a Nikon D90 digital reflex camera (Nikon Corporation, Tokyo, Japan) equipped with a telephoto lens with a focal length of $f=18-200 \mathrm{~mm}$. Two groups ("Grand Bassin": 46 individuals; "Petit Bassin": 57 individuals) out of the three served as test groups. Eight portraits of adult animals (i.e. females from the age of five and males from the age of seven) with a neutral facial expression (see Teufel et al. 2010) were chosen from each group, with the same number of males and females (Fig. 1). All faces were cropped using Adobe Photoshop CS3 (Adobe Systems, Incorporation, San Jose, California, USA), so that the facial features were fitted into a circle of a diameter of $17 \mathrm{~cm}$. The luminance did not differ significantly between groups (Mann-Whitney $U=24.5, N 1=N 2=8, P=0.43$ ). Photographs were printed on matte photo paper to avoid any reflection during the testing session. This resulted in a set of 16 stimuli that served both as 'own group' or 'other group' stimuli, depending on the group in which the experiments were conducted. To control for possible effects of the experimental setting, we introduced an additional condition in which a white sheet of paper was shown.

\section{Experimental design}

Experiments were conducted in the tourist area of the park. The experimenter sat square on a bench (Fig. 2) and placed small amounts of food in front of her as an incentive for the animals to approach. Whenever a subject jumped on the

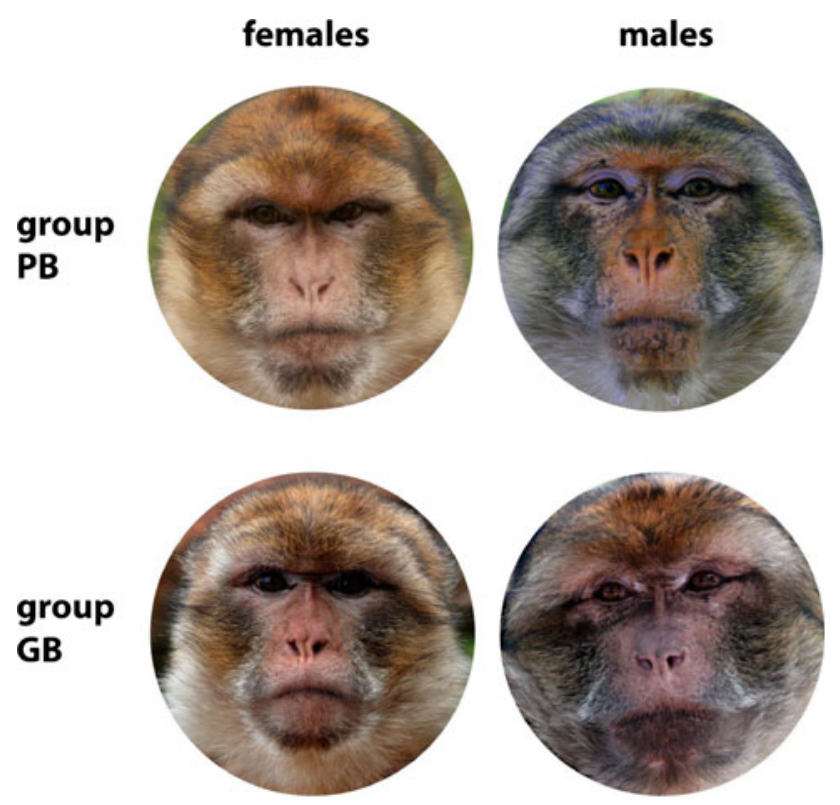

Fig. 1 Example of portrait photographs of the two tested groups used as stimuli ( $G B$ Grand Bassin, $P B$ Petit Bassin)

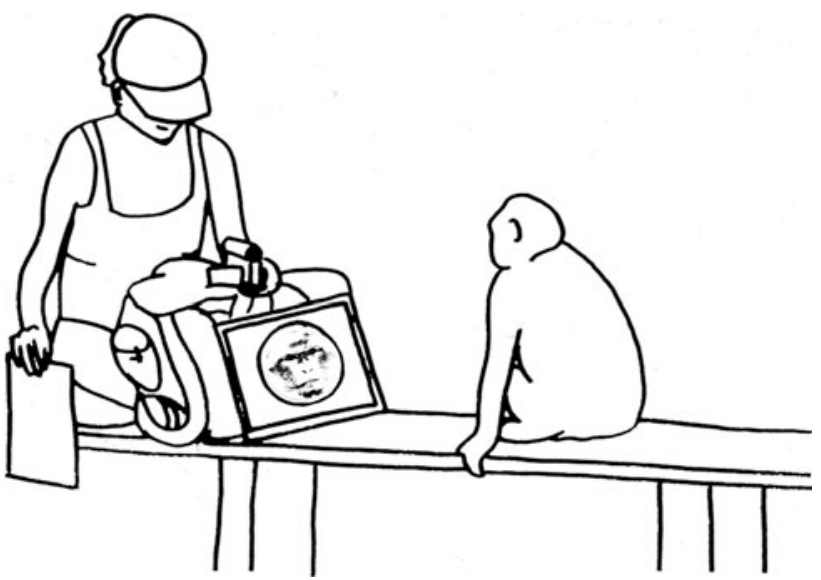

Fig. 2 Experimental set-up. Visitor benches served as test locations. The experimenter positioned herself at the angle with the covered stimuli screen placed in front of her. Trials started whenever a subject accessed the setting and looked towards the experimenter (artwork by K. R.)

bench and looked towards the experimenter, the cover occluding the photograph was carefully removed and the behaviour of the monkey recorded on video. The experimenter wore a baseball cap and looked at the screen of the camera that was turned in a 90 degree angle so that the experimenter could film the behaviour while looking down. The experiments were conducted 'blind', i.e. the experimenter was unaware whether the picture was showing a member of the own or the other group, or nothing. Recording was ended when the subject left the bench or looked away for more than $60 \mathrm{~s}$, which also ended the trial. After each trial, the experimenter noted the stimulus number, date, time, group and subject ID. None of the monkeys had ever participated in an experimental study that employed visual representations of monkeys before. Apart from the small amount of food used as a lure, they were not rewarded and attended the test trials voluntarily. To avoid habituation, each subject was only tested once on a given day.

Videotapes were converted to .avi files (25 frames/s). The video recordings were analysed blind to the experimental condition on a frame-by-frame basis using Adobe Premiere Pro CS4 (Adobe Systems, Incorporation, San Jose, California, USA). Firstly, we determined the 'total looking duration' (total sum of all views a subject had made during one trial). The onset of a look was defined as the frame in which the subject's gaze was first directed to the stimulus region. The endpoint was defined as the frame the subject's eyes were closing before the subject turned its head away. The inter-observer reliability between three observers was high: The mean Pearson correlation coefficient for the estimation of looking time for 3 observers for a subset of randomly selected looking events was 0.998 ( $N=27$ trials). In addition to the looking time, we 
analysed the occurrence of three categories of behavioural responses on a yes/no basis: (1) self-directed behaviour (yawn and self-scratch), (2) approach/gesture (approach, lift eyebrow, head bob, lip-smack and drag leg) and (3) picture manipulation (touch photo, bite into photo, turn photo and smell at photo). These behaviours typically accompanied the looking response. The inter-observer reliability was estimated for a random sample of $N=20$ trials across 3 observers. The agreement for the behavioural categories was good to excellent: Fleiss' fixed-marginal kappa was 0.73 for self-directed behaviours, 0.86 for approach/gesture and 0.87 for manipulation. Fleiss' kappa was calculated using the online kappa calculator (Randolph 2008).

In total, we tested 70 subjects (Table 1) in 197 trials, with 11 tested as juveniles (up to the age of 3 years) only, 6 tested as juveniles and adults (in 2008 and 2010, respectively) and 53 tested as adults ( $>3$ years of age). Subjects were on average tested 1.6 times in 2008 and 2.3 times in 2010; the maximum frequency in 2008 was 5 for one subject and 3 or less for the rest; in 2010, one subject was tested 7 times, two subjects 5 times and the rest 4 times or less.

\section{Statistical analyses}

Because subjects were tested repeatedly, we used a mixed linear model with experimental conditions as fixed factor and subject as random factor, applying the restricted maximum likelihood estimation (REML). We first assessed whether there were differences in responses to facial stimuli compared to the control stimulus. Next, we tested whether subjects showed differential responses to pictures from their own vs. the other group. To test for age-related differences, we used the 'generalized estimating equations (GEE) procedure', a generalized mixed model to test binary response variables (binary logistic link function). We used 'picture manipulation', 'approach/gesture' and 'selfdirected behaviour' as response variable, subject as random factor to account for multiple testing, and experimental condition and age category as predictor variables. All statistical analyses were conducted using PASW 18.

Table 1 Overview of the subjects from the two social groups (PB: Petit Bassin and GB: Grand Bassin) that participated in the study

\begin{tabular}{lll}
\hline & PB & GB \\
\hline Adult males & 17 & 8 \\
Adult females & 12 & 17 \\
Juvenile males & $5(2)$ & 5 \\
Juvenile females & $5(1)$ & $7(3)$
\end{tabular}

Note that 6 juvenile subjects indicated in brackets that were tested in 2008 were tested again as adults in 2010 so that the total number in this table is 76 , while the total number of individuals is 70

\section{Results}

Subjects looked significantly longer at pictures of faces than at the empty sheet of paper (facial stimuli $X \pm$ SEM $6.9 \pm 0.7 \mathrm{~s}(N=177)$ compared to $1.3 \pm 0.3 \mathrm{~s}$ for control stimuli $\left.(N=20) ; F_{1,194.1}=7.2 ; P=0.008\right)$. Juveniles did not show differential responses to pictures of their own and another group's members ('own group': $11.0 \pm 2.3 \mathrm{~s}$; $N=33$, 'other group': $10.6 \pm 1.4 \mathrm{~s} ; N=32 ; F_{1,61.1}=$ 0.66; $P=0.798$; Fig. 3). In contrast, adult Barbary macaques spent significantly more time looking at pictures of other group members $(5.9 \mathrm{~s} \pm 1.1 ; N=58)$ than at pictures from their own group members (3.3 $\mathrm{s} \pm 0.5 ; N=54)$; $F_{1,106.5}=5.09 ; P=0.026$, Fig. 3 ). Across categories, juvenile Barbary macaques showed significantly longer responses than adults (juveniles: $10.8 \pm 1.4 \mathrm{~s}$, adults: $4.6 \pm 0.6 \mathrm{~s} ; F_{1,99.9}=20.37 ; P<0.000$; Fig. 3 ).

We found no differences in the occurrence of any of the three behavioural categories in relation to experimental condition (manipulation $P>0.9$; approach/gesture $P>0.17$; self-directed $P>0.4)$. Juveniles manipulated the picture (Wald $\chi_{1}^{2}=19.9, P<0.001$ ) or showed approaches and gestures (Wald $\chi_{1}^{2}=33.4, P<0.001$ ) significantly more frequently than did adults, while there were no significant differences in the occurrence of self-directed behaviours between juveniles and adults (Wald $\chi_{1}^{2}=0, P=1$; Table 2).

\section{Discussion}

The experiments revealed that adult Barbary macaques show a greater interest in pictures of animals from a neighbouring group compared to pictures of conspecifics

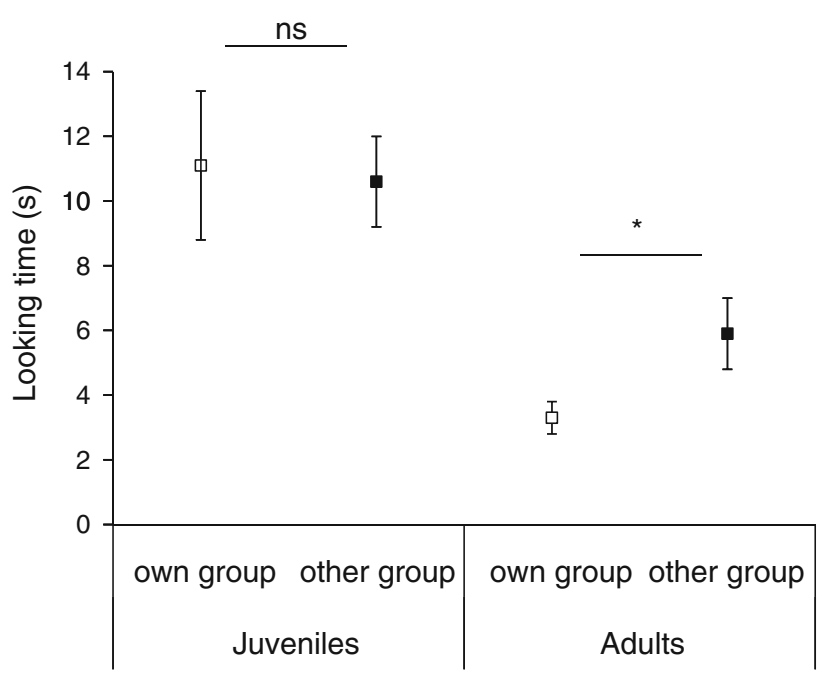

Fig. 3 Mean $( \pm$ SEM) total looking time of juveniles and adults to portraits of group members and nongroup members 
Table 2 Age-related differences in behaviour patterns in response to stimulus presentation

\begin{tabular}{llc}
\hline Behaviour category & Juveniles $(\%)$ & Adults $(\%)$ \\
\hline Picture manipulation & 47.4 & 7.6 \\
Approach/gesture & 71.2 & 21.2 \\
Self-directed & 57.6 & 57.6 \\
\hline
\end{tabular}

The occurrence of behaviour is given as the percentage of trials in which the behaviour was observed

from their own group, indicating that they distinguish between their own and other groups' members. There are two possible explanations why the adult monkeys would respond more strongly to the pictures from members of the other group. Either they show more interest because the faces are unfamiliar or because they recognize them as members of another, potentially hostile group. The present experiments do not allow us to distinguish between the two possibilities. Whatever the case, our finding suggests that the monkeys are able to memorize the faces of up to at least 57 individuals. These results corroborate the findings from Pokorny and de Waal (2009b) who tested three brown lemurs in a match-to-sample task. These monkeys lived in relatively small groups of up to 14 individuals, which raised the question whether group size may have an effect on the results.

Our results provide evidence that experience during development plays a role in the development of individual recognition (Fagot et al. 2010), since the juvenile subjects did not distinguish between subjects from their own and the other group. There are two possible explanations for this observation. Firstly, it is possible that they are not able to distinguish their group members from other Barbary macaques. This might indicate that it takes some time until the facial characteristics of one's group members are learned. Second, it might be possible that they do not understand that the photographs depict conspecifics, and thus, they were not able to distinguish between the categories (see below). To test the first hypothesis, it would be necessary to run such tests with animals living in smaller groups. If young monkeys in smaller groups develop the ability to distinguish between photographs of members of their own and another group sooner than young monkeys living in a large group, then the hypothesis that memory load is crucial would be supported. Experience or 'perceptual expertise' also shapes the preference for speciesspecific faces. Specifically, both humans and monkeys looked longer at the eyes of photographic representations of conspecifics compared to the respective heterospecific's eyes (Dahl et al. 2009). Interestingly though, a preference for conspecific faces does not seem to be innate, as evidenced by a study on Japanese monkeys that were reared in isolation for 6-24 months. Directly after the end of the deprivation, the monkeys showed a preference for both monkey and human faces compared to pictures of toys, while normally reared monkeys showed a clear preference for conspecific faces (Sugita 2008).

Both juveniles and adults showed a considerable amount of self-directed behaviours like scratching when being exposed to the photographic representations. Such behaviours are typically considered to be expressions of anxiety and discomfort (Castles et al. 1999). In addition, the juveniles touched, sniffed at or lip-smacked to the photographs significantly more frequently than adults, suggesting that they did not understand the dual nature of these pictures, in the sense that these constitute both pictures and representations of something else. These observations corroborate previous findings obtained from baboons, Papio anubis, which had no previous experience with pictures (Parron et al. 2008). In this study, subjects were confronted with pictures of bananas and real pebbles or photographic representations of pebbles. Subjects preferentially reached out to the pictures of the bananas, suggesting that they did not understand that these were just pictures. This would be congruent to performance of children, for which there is little evidence that they develop such an understanding before the age of 2.5 years (DeLoache 2004).

Despite these failures of young monkeys in experimental settings, personal observations on the behaviour of infant baboons towards newly immigrant males indicate that at an age of about half a year, they respond very differently towards a new male than to a familiar one (J. Fischer, pers. observation). These baboons lived in a troop of more than 80 individuals, indicating that the animals' ability to remember the features of large numbers of subjects is probably even larger than demonstrated here. Moreover, this capacity to remember individual features and also to understand the relationship between others may not be restricted to one's own species. There is anecdotal evidence that one female baboon, Ahla, who was trained to work as a goat herder, correctly identified the individual bleat of newborn goats and would carry them to their mother (Hoesch 1961; cf. Cheney and Seyfarth 2007).

To conclude, we have shown that adult Barbary macaques are able to memorize the faces of a large number of animals and use this knowledge to distinguish between photographs of their own group and another group's members. Although this finding per se does not demonstrate that they are able to individually recognize their group members, this seems to be highly likely. Horses, for instance, reveal cross-modal recognition of individuals (Proops et al. 2009). In the light of the finding that most group-living nonhuman primate species, including Barbary macaques (Deag 1971), respond fiercely during encounters with other groups, but adapt their behaviour in relation to whether they interacted more or less frequently with these 
other groups, suggest that nature has put a large premium on the ability to memorize the individual characteristics of other conspecifics. Whether this ability largely rests on the processing of familiarity or indeed recognition of particular individuals remains an issue for further investigation. From a functional point of view, it is irrelevant which of the mechanisms is employed, as both result in the same behaviour.

Acknowledgments We are grateful to Ellen Merz for permission to conduct this study at 'La Forêt des Singes' at Rocamadour, and the whole crew of animal keepers for assistance in obtaining individual codes of the monkeys tested in the trials. We thank Brandon Wheeler, Dorothy Cheney, Stephen Shepherd and the anonymous reviewers for discussion and constructive criticism.

Open Access This article is distributed under the terms of the Creative Commons Attribution Noncommercial License which permits any noncommercial use, distribution, and reproduction in any medium, provided the original author(s) and source are credited.

\section{References}

Bergman TJ, Beehner JC, Cheney DL, Seyfarth RM (2003) Hierarchical classification by rank and kinship in baboons. Science 302:1234-1236. doi:10.1126/science.1087513

Bovet D, Vauclair J (2000) Picture recognition in animals and humans. Behav Brain Res 109:143-165

Briefer E, Rybak F, Aubin T (2008) When to be a dear enemy: flexible acoustic relationships of neighbouring skylarks, Alauda arvensis. Anim Behav 76:1319-1325. doi:10.1016/j.anbehav. 2008.06.017

Castles DL, Whiten A, Aureli F (1999) Social anxiety, relationships and self-directed behaviour among wild female olive baboons. Anim Behav 58:1207-1215

Charrier I, Pitcher BJ, Harcourt RG (2009) Vocal recognition of mothers by Australian sea lion pups: individual signature and environmental constraints. Anim Behav 78:1127-1134. doi: 10.1016/j.anbehav.2009.07.032

Cheney DL, Seyfarth RM (1982) Recognition of individuals within and between groups of free-ranging vervet monkeys. Am Soc Zool 22:519-529

Cheney DL, Seyfarth RM (2007) Baboon metaphysics. University of Chicago Press, Chicago

Coulon M, Deputte BL, Heyman Y, Baudoin C (2009) Individual recognition in domestic cattle (Bos taurus): evidence from 2DImages of heads from different breeds. Plos One 4:e4441. doi: 10.1371/journal.pone.0004441

Dahl CD, Logothetis NK, Hoffman KL (2007) Individuation and holistic processing of faces in rhesus monkeys. P Roy Soc Lond B Bio 274:2069-2076. doi:10.1098/rspb.2007.0477

Dahl CD, Wallraven C, Bülthoff HH, Logothetis NK (2009) Humans and macaques employ similar face-processing strategies. Curr Biol 19:509-513. doi:10.1016/j.cub.2009.01.061

Dahl CD, Logothetis NK, Bulthoff HH, Wallraven C (2010) The Thatcher illusion in humans and monkeys. P Roy Soc Lond B Bio 277:2973-2981. doi:10.1098/rspb.2010.0438

Dasser V (1988) A social concept in java monkeys. Anim Behav $36 \cdot 225-230$
Deag JM (1971) Intergroup encounters in the wild Barbary macaque, Macaca sylvanus L. In: Michael RP, Crook JH (eds) Comparative ecology and behaviour of primates. Academic Press, London, pp 315-373

DeLoache JS (2004) Becoming symbol-minded. Trends Cogn Sci 8:66-70. doi:10.1016/j.tics.2003.12.004

Dufour V, Pascalis O, Petit O (2006) Face processing limitation to own species in primates: a comparative study in brown capuchins, Tonkean macaques and humans. Behav Process 73:107-113. doi:10.1016/j.beproc.2006.04.006

Fagot J, Thompson RKR, Parron C (2010) How to read a picture: lessons from nonhuman primates. P Natl Acad Sci USA 107:519-520. doi:10.1073/pnas.0913577107

Fischer J (2004) Emergence of individual recognition in young macaques. Anim Behav 67:655-661. doi:10.1016/j.anbehav. 2003.08.006

Hammerschmidt K, Todt D (1995) Individual differences in vocalizations of young Barbary macaques (Macaca sylvanus): a multiparametric analysis to identify critical cues in acoustic signalling. Behaviour 132:381-399

Herbinger I, Papworth S, Boesch C, Zuberbuhler K (2009) Vocal, gestural and locomotor responses of wild chimpanzees to familiar and unfamiliar intruders: a playback study. Anim Behav 78:1389-1396. doi:10.1016/j.anbehav.2009.09.010

Hoesch W (1961) Über Ziegen hütende Bärenpaviane (Papio ursinus ruacana Shortridge). Zeitschrift für Tierpsychologie 18(3):297301. doi:10.1111/j.1439-0310.1961.tb00421.x

Humphrey NK (1974) Species and individuals in the perceptual world of monkeys. Perception 3:105-114

Janik VM, Sayigh LS, Wells RS (2006) Signature whistle shape conveys identity information to bottlenose dolphins. P Natl Acad Sci USA 103:8293-8297. doi:10.1073/pnas.0509918103

Kondo N, Izawa EI, Watanabe S (2010) Perceptual mechanism for vocal individual recognition in jungle crows (Corvus macrorhynchos): contact call signature and discrimination. Behaviour 147:1051-1072. doi:10.1163/000579510x505427

Langen TA, Tripet F, Nonacs PN (2000) The red and the black: habituation and the dear-enemy phenomenon in two desert Pheidole ants. Behav Ecol Sociobiol 48:285-292

Marechal L, Genty E, Roeder JJ (2010) Recognition of faces of known individuals in two lemur species (Eulemur fulvus and E. macaco). Anim Behav 79:1157-1163. doi:10.1016/j.anbehav. 2010.02.022

Müller CA, Manser MB (2007) 'Nasty neighbours' rather than 'dear enemies' in a social carnivore. P Roy Soc Lond B Bio 274:959-965. doi:10.1098/rspb.2006.0222

Parr LA, Winslow JT, Hopkins WD, de Waal FBM (2000) Recognizing facial cues: individual discrimination by chimpanzees (Pan troglodytes) and rhesus monkeys (Macaca mulatta). J Comp Psychol 114:47-60

Parron C, Call J, Fagot J (2008) Behavioural responses to photographs by pictorially naive baboons (Papio anubis), gorillas (Gorilla gorilla) and chimpanzees (Pan troglodytes). Behav Process 78:351-357. doi:10.1016/j.beproc.2008.01.019

Pokorny JJ, de Waal FBM (2009a) Face recognition in capuchin monkeys (Cebus apella). J Comp Psychol 123:151-160. doi: 10.1037/a0014073

Pokorny JJ, de Waal FBM (2009b) Monkeys recognize the faces of group mates in photographs. $P$ Natl Acad Sci USA 106:21539-21543. doi:10.1073/pnas.0912174106

Proops L, McComb K, Reby D (2009) Cross-modal individual recognition in domestic horses (Equus caballus). P Natl Acad Sci USA 106:947-951. doi:10.1073/pnas.0809127105

Racca A, Amadei E, Ligout S, Guo K, Meints K, Mills D (2010) Discrimination of human and dog faces and inversion responses 
in domestic dogs (Canis familiaris). Anim Cogn 13:525-533. doi:10.1007/s10071-009-0303-3

Randolph JJ (2008) Online kappa calculator

Sebe F, Duboscq J, Aubin T, Ligout S, Poindron P (2010) Early vocal recognition of mother by lambs: contribution of low- and highfrequency vocalizations. Anim Behav 79:1055-1066. doi:10.1016/ j.anbehav.2010.01.021

Seyfarth RM, Cheney DL (1988) Do monkeys understand their relations? In: Byrne RW, Whiten A (eds) Machiavellian intelligence: social expertise and the evolution of intellect in monkeys, apes, and humans. Oxford University Press, Oxford, England, pp 69-84

Shettleworth SJ (2010) Cognition, evolution and behavior. Oxford University Press, Oxford

Sugita Y (2008) Face perception in monkeys reared with no exposure to faces. Proc Natl Acad Sci USA 105:394-398. doi:10.1073/ pnas.0706079105

Teufel C, Gutmann A, Pirow R, Fischer J (2010) Facial expressions modulate the ontogenetic trajectory of gaze-following among monkeys. Dev Sci. doi:10.1111/j.1467-7687.2010.00956.x
Thompson RKR, Oden DL (2000) Categorical perception and conceptual judgments by nonhuman primates: the paleological monkey and the analogical ape. Cognitive Sci 24:363-396

Tibbetts EA, Dale J (2007) Individual recognition: it is good to be different. Trends Ecol Evol 22: 529-537. doi:10.1016/j.tree. 2007.09.001

Turckheim GD, Merz E, Fa JE (1984) Breeding Barbary macaques in outdoor open enclosures. In: Fa JE (ed) The Barbary macaque: a case study in conservation. Plenum Press, New York, pp 241-261

Van der Velden J, Zheng Y, Patullo BW, Macmillan DL (2008) Crayfish recognize the faces of fight opponents. Plos One 3:e1695. doi:10.1371/journal.pone.0001695

Whiting M (1999) When to be neighbourly: differential agonistic responses in the lizard Platysaurus broadleyi. Behav Ecol Sociobiol 46:210-214

Wilkinson A, Specht HL, Huber L (2010) Pigeons can discriminate group mates from strangers using the concept of familiarity. Anim Behav 80:109-115. doi:10.1016/j.anbehav.2010.04.006 